\title{
Enfermedad por meningococo, Neisseria meningitidis: perspectiva epidemiológica, clínica y preventiva
}

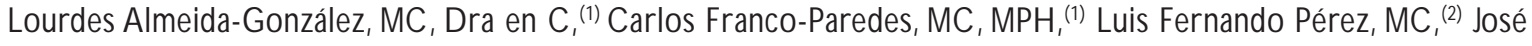 \\ Ignacio Santos-Preciado, MD, M SC, BSc.(1)
}

Almeida-González L, Franco-Paredes C, Pérez LF, Santos-Preciado Jl. Enfermedad por meningococo, N eisseria meningitidis: perspectiva epidemiológica, clínica y preventiva. Salud Publica Mex 2004;46:438-450. El texto completo en inglés de este artículo está disponible en: http://www.insp.mx/salud/index.html

\section{Resumen}

La meningitis bacteriana continúa siendo uno de los grandes problemas de la salud pública mundial. En particular, la infección por N eisseria meningitidis afecta tanto a países desarrollados como subdesarrollados, y se presenta en formas endémicas y epidémicas. La enfermedad meningo cóccica se puede manifestar clínicamente no sólo como meningitis, sino con cuadros fulminantes de meningococcemia. La persistencia de $\mathrm{N}$. meningitidis se debe al gran porcentaje de portadores y a la dinámica de transmisión de la bacteria. A proximadamente 500 millones de personas en el mundo son portadoras de N . meningitidis en la naso faringe. Los factores de transmisiblidad identificados han sido el tabaquismo activo o pasivo, la presencia de infecciones virales del tracto respiratorio superior, épocas de sequía, y el hacinamiento. Por lo anterior, se han descrito brotes de enfermedad meningo cóccica en cuarteles militares, escuelas, cárceles y dormitorios. Algunos determinantes que permiten la invasión sistémica incluyen daños en la mucosa nasofaríngea de portadores, cepas virulentas con formación de cápsula, ausencia de anticuerpos bactericidas y deficiencias del sistema del complemento. El control de la enfermedad meningocóccica en circunstancias endémicas y epidémicas se logra por el tratamiento de casos con antibióticos adecuados (penicilina, ceftriaxona o cloranfenicol), la quimioprofilaxis de contactos cercanos (ciprofloxacina, rifampicina o ceftriaxona), y la vigilancia clínica de éstos. Sin embargo, es funda-

\author{
Almeida-González L, Franco-Paredes C, \\ Pérez LF, Santos-Preciado JI. \\ Meningococcal disease caused by Neisseria meningitidis: \\ epidemiological, clinical, and preventive perspectives. \\ Salud Publica Mex 2004;46:438-450. \\ The English version of this paper \\ is available at: http://www.insp.mx/salud/index.html
}

(1) Hospital Infantil de México Federico Gómez. México, DF, México.

(2) Hospital Central de San Luis Potosí. San Luis Potosí, México.

\begin{abstract}
A bstract
Bacterial meningitis constitutes a significant global public health problem. In particular, Neisseria meningitidis continues to be a public health problem among human populations in both developed and developing countries. Meningococcal infection is present as an endemic and an epidemic disease. Meningo coccal disease is manifested not only as meningitis, but also as meningo coccemia. The latter is usually fulminant.The glo bal persistence of $\mathrm{N}$. meningitidis is due to the significant number of carriers and the dynamics of transmission and disease. Approximately 500 million people worldwide are carriers of the bacterium in their nasophar ynx. Multiple factors have been identified that predispose to the transmissibility of $\mathrm{N}$. meningitidis, including active or passive inhalation tobacco smoking, upper viral respiratory tract infections, drought seasons, and overcrowding. These factors explain the frequent occurrence of outbreaks in military barracks, schools, prisons, and do rmitories. Some of the determinants of invasiveness of the bacteria include nasopharyngeal mucosal damage in colonized individuals, virulence of the strains, absence of bactericidal antibodies, and deficiencies of the complement system. D uring both endemic and epidemic scenarios of meningo coccal disease, control measures should include treating the cases with appropriate antimicrobial therapy (penicillin, ceftriaxone, or chloramphenicol); providing chemoprophylactic drugs to contacts (rifampin or ciprofloxacin), and close ob-
\end{abstract}

Fecha de recibido: 17 de marzo de 2004 • Fecha de aprobado: 21 de julio de 2004

Solicitud de sobretiros: José Ignacio Santos Preciado, D irector General. Hospital Infantil de México Federico Gómez. Doctor Márquez N 0. 162, colonia D octores, D elegación Cuauhtémoc, 06720 México, DF, México.

Correo electrónico: jisantos@ himfg.com.mx 
mental subrayar que la clave para el control efectivo de la enfermedad meningocóccica es la inmunoprofilaxis. Las vacunas disponibles incluyen las de polisacáridos monovalentes 0 bivalentes (serogrupos $A$ y $C$ ), tetravalentes $(A, C, Y$, W-135), la conjugada (C) o la combinada de proteínas de membrana celular y polisacárido (B y C). Recientemente nos hemos visto forzados a establecer planes nacionales de respuesta que incluyen la disponibilidad de vacuna y de medicamentos para quimioprofilaxis, debido a que se ha documentado un incremento de casos de enfermedad por $N$. meningitidis, serogrupo $C$, en el país. Es por lo anterior que esta revisión está dirigida a proporcionar al personal de salud un recordatorio de los aspectos relevantes de la epidemio lo gía, y de los clínicos y preventivos de la enfermedad meningocóccica. El texto completo en inglés de este artículo está disponible en: http://www.insp.mx/salud/ index.html

Palabras clave: Neisseria meningitidis; meningitis bacteriana; meningococcemia; púrpura fulminante servation of contacts. N evertheless, the key to effective control and prevention of meningococcal disease is immunoprophylaxis.Available vaccines include the polysaccharide monovalent, bivalent (serogroups $A, C)$, or tetravalent $(A$, $C, Y, W-135$ serogroups) vaccines; conjugate vaccine (serogroup $C$ ); and the combined vaccine with outer membrane proteins and polysaccharide (serogroups $B, C$ ). Due to a recent increase in case reporting of serogroup $C \mathrm{~N}$. meningitidis in Mexico, we have developed a national response strategy that includes availability of vaccines and medications for chemoprophylaxis. This review aims at providing health care workers with updated information regarding the epidemiological, clinical, and preventive aspects of meningococcal disease. The English version of this paper is available at: http://www.insp.mx/salud/index.html

Key words: N eisseria meningitidis; meningitis, bacterial; meningococcemia; fulminant purpura
L a enfermedad meningocóccica es una enfermedad contagiosa ocasionada por la bacteria Gram-negativa Neisseria meningitidis o meningococo. ${ }^{1}$ La infección ocurre en formas endémicas y epidémicas, tanto en países en desarrollo como en países desarrollados a pesar de haber avances importantes en la epidemiología, diagnóstico y tratamiento de la enfermedad meningocóccica. ${ }^{1,2}$ La aparición de casos de meningococo en una población se ha asociado tradicionalmente a gran estrés social y médico, debido al carácter fulminante de las presentaciones clínicas de la enfermedad. ${ }^{3-5}$ El impacto histórico de la enfermedad y su devastadora persistencia a escala mundial se deben a que las vacunas hasta el momento disponibles son imperfectas, y a que no hemos logrado identificar las medidas de control necesarias para disminuir significativamente el nivel de portadores asintomáticos. ${ }^{6}$ De la misma forma, se ha logrado identificar que el meningococo es una bacteria con una gran patogenicidad y virulencia. En condiciones habituales, existen cientos de personas con colonización del tracto respiratorio superior por cada caso de enfermedad meningocóccica. Si la bacteria matara a todas las personas infectadas, el microrganismo cometería suicidio, ya que no tiene otros huéspedes o reservorios en la naturaleza. ${ }^{6,7}$

Neisseria meningitidis es la causa más común de meningitis bacteriana en el mundo occidental, más significativamente en aquellos países que han introducido la inmunización universal contra Haemophilus influenzae tipo b. Además, la mortalidad por la enfermedad meningocóccica es considerablemente mayor que la producida por la meningitis debida al $H$. influenzae y evoluciona en forma de brotes y epidemias en el ámbito mundial, mientras que la última es esencialmente esporádica. ${ }^{1,7} \mathrm{La}$ enfermedad meningocóccica puede tratarse con relativo éxito, en casos individuales de la enfermedad, mientras que somos incapaces, hasta el momento, de conocer con profundidad su comportamiento epidemiológico. Para el personal de salud y los epidemiólogos resulta una paradoja el hecho de que en casi 200 años de observación e investigaciones se han recopilado muchos conocimientos acerca de su transmisión, fisiopatología, respuesta inmune y de los determinantes de virulencia. Sin embargo, no podemos explicar por qué un individuo en particular que adquiere este microrganismo desarrolla la forma invasiva de la enfermedad, mientras que otros cientos de personas que igualmente lo adquieren desarrollan inmunidad a la infección. ${ }^{8}$

Existen dos formas principales de manifestación clínica de la enfermedad: la meningitis meningocóccica, y la meningococcemia o septicemia meningocóccica. La primera, es la forma más común, se presenta principalmente durante epidemias y tiene buen pronóstico si los casos se tratan adecuadamente. ${ }^{1,7}$ La meningococcemia, en contraste, es menos frecuente pero altamente letal aun con tratamiento, y se caracteriza por el hallazgo de hemocultivos positivos de Neisseria meningitidis aunados a una respuesta inflamatoria sistémica exagerada, asociada a endotoxinemia. ${ }^{1,9}$ Aquellos casos en los que se presentan meningitis y bacteriemia simultáneamente son considerados usualmente como 
meningitis. La septicemia meningocóccica es considerada una urgencia médica y casi ninguna otra enfermedad infecciosa lleva tan rápido a la muerte., ${ }^{2,3}$

\section{Epidemiología mundial de la enfermedad por meningococo}

Los primeros informes de esta enfermedad se dieron en 1805, por Vieusseux, durante una epidemia que azotó las afueras de Ginebra, Suiza. ${ }^{1,8}$ Sin embargo, el agente causal de la enfermedad fue identificado por Weichselbaum hasta 1887. En el siglo XX ocurrieron grandes epidemias durante la Primera y Segunda Guerras Mundiales. ${ }^{2}$ En el continente africano, particularmente en la región subsahariana, se han descrito epidemias de meningococo desde principios del mismo siglo, exacerbadas en sus últimas décadas por peregrinaciones religiosas de musulmanes a la zona de La Meca, en Arabia Saudita. ${ }^{2,10}$ Desde tiempos inmemoriales existen descripciones de meningitis meningocóccica en Sudán; sin embargo, se piensa que la enfermedad se dispersó al norte de Africa alrededor de $1880 .^{2}$ Después de la Segunda Guerra Mundial, la meningitis epidémica meningocóccica causada por el serogrupo A ha sido escasa en países desarrollados. No obstante, esta variedad persiste con un impacto devastador en Africa subsahariana. Durante la segunda mitad del siglo XX, el serogrupo A ha sido la forma predominante; sin embargo, los otros serogrupos (B, C, Y, W-135 y X) han participado en los últimos años. Las circunstancias que han ocasionado estas epidemias continúan sin poder definirse claramente, pero han sido relacionadas con diversos factores como el hacinamiento, el desplazamiento de poblaciones, factores climáticos y la virulencia de las cepas circulantes. En 1996, particularmente en el cinturón meníngeo, hubo un número sustancial de casos de meningitis con mortalidad elevada. El informe mundial señala que hubo 188341 casos, con 20000 muertes acaecidas entre enero y octubre de $1996.2,10$

Fuera de Africa, y desde 1970, diversas epidemias han azotado al mundo. La incidencia de la enfermedad se ha incrementado en diversos países de América, Asia y Europa con un patrón caracterizado por brotes recurrentes y enfermedad esporádica persistente. Se observó un incremento significativo en Italia, Portugal, España y Yugoslavia en 1970 y 1971; en Bélgica, en 1972; en Argentina, 1974; Reino Unido, entre 1974 y 1975, y en Francia en 1973 y 1978. En Finlandia, Mongolia y en la Unión Soviética, entre 1973 y 1974, fueron descritos diversos brotes, y en Brasil también han ocurrido varios desde $1971 .{ }^{1,2,7}$
Los serogrupos A, B, y C producen la mayoría de los casos a escala mundial, siendo los serogrupos B y $C$ responsables por la mayoría de éstos en Europa y América. Los serogrupos A y C predominan en Asia y Africa. ${ }^{1}$ Estados Unidos de América (EUA), Suecia e Israel son los únicos países en los cuales ha habido un aumento en la incidencia del serogrupo $Y$ en la última década. ${ }^{11}$ La enfermedad meningocóccica por el serogrupo B causó 68\% de los casos en Europa, entre 1993 y 1996. En la década de los setenta se informó que una clona del serogrupo B denominada ET-5 fue responsable de brotes en Europa Occidental y Central, así como en Suramérica. En la década de los ochenta, hubo olas de enfermedad meningocóccica que se diseminaron a India, Nepal y Africa. ${ }^{2}$ En Cuba, de 1982 a 1984, y en Chile, entre 1986 y 1993, hubo epidemias de enfermedad meningocóccica por el serogrupo B. ${ }^{11}$

En EUA la causa más frecuente de brotes de meningitis por $N$. meningitidis ha sido el serogrupo C; sin embargo, los descritos en 2000, en pacientes que regresaron del peregrinaje a Arabia Saudita, se asociaron al serogrupo W-135. ${ }^{10,11}$ En los últimos años, y principalmente entre 1996 y 1998, el serogrupo Y ocasionó aproximadamente un tercio de los casos. ${ }^{10}$ No obstante, los serogrupos C y B continúan siendo los principalmente asociados a enfermedad esporádica. ${ }^{1,11,12-16}$ Mientras tanto, el último brote que provocó gran impacto en el continente americano se presentó en Uruguay, en 2001, y fue ocasionado por los serogrupos B y C. ${ }^{17}$

La definición de enfermedad epidémica depende de las tasas de incidencia de base de cada país o región. En comparación con las epidemias explosivas que se dan en el cinturón de meningitis en Africa, las epidemias que han azotado a Europa y al continente americano son moderadas, debido a que las tasas de ataque durante una epidemia en estas regiones han sido menores que las tasas de incidencia endémicas en los países africanos. ${ }^{1,2}$

\section{Mecanismos de transmisión}

La transmisión de N. meningitidis se realiza por contacto de persona a persona, o por la inhalación de gotas respiratorias que contienen meningococos. ${ }^{1,2,7} \mathrm{Al}$ no sobrevivir en el ambiente y no tener un reservorio en animales, el hombre constituye su única posibilidad de sobrevivir y propagarse. El contacto es usualmente con un enfermo o un portador asintomático que aloja a la bacteria en la nasofaringe y que la transmite por gotas respiratorias o secreciones orales. Neisseria meningitidis es susceptible a cambios de temperatura y a 
la desecación y, por lo tanto, la infección no se transmite por fomites. Los actos de toser o estornudar contribuyen al mecanismo de transmisión, ${ }^{1,2}$ por lo que no resulta sorpresivo que la tasa de colonización puede ser mayor a $50 \%$ en escuelas, internados, o en cuarteles militares, especialmente durante periodos asociados a un incremento en infecciones virales del tracto respiratorio superior. ${ }^{8,18}$ Se calcula que en el mundo existen cerca de 500 millones de portadores de la bacteria en la nasofaringe. La tasa de portadores es muy baja durante la infancia y muy alta en adolescentes y adultos jóvenes. En poblaciones abiertas la transmisión de $N$. meningitidis es relativamente lenta y es mayor en poblaciones que viven en áreas confinadas, y se exacerba por tabaquismo e infecciones respiratorias.

La prevalencia del estado de portador es variable y no se correlaciona con el riesgo de un brote o epidemia. ${ }^{8}$ Históricamente se ha sugerido que tasas de colonización de más de $20 \%$ en la población podrían estar asociadas con el inicio de un brote. ${ }^{7}$ Sin embargo, los estudios epidemiológicos moleculares recientes han demostrado que en los casos de enfermedad meningocóccica las cepas virulentas aisladas, que han ocasionado los casos, se encontraron únicamente en una pequeña subpoblación del total de la colonizada, y es en esta pequeña subpoblación en donde la enfermedad meningocóccica está confinada. Por lo tanto, identificar un porcentaje elevado de colonización simplemente indica que las condiciones son propicias para que una cepa virulenta se pueda diseminar. ${ }^{8,18}$

La contagiosidad de la enfermedad se desvanece rápidamente en un enfermo después de iniciar la terapia antimicrobiana. En trabajadores de la salud, responsables del cuidado de un paciente con enfermedad por meningococo, únicamente se contagian aquellos que han estado expuestos directamente a secreciones del paciente. ${ }^{2}$ Se ha logrado identificar que cuando hay un caso de enfermedad por meningococo en un infante el riesgo de que uno de sus hermanos o hermanas se infecte es de 2 a $3 \%$, y la tasa de ataque para los contactos intradomicilarios es de 2 a 4 por 1000 de éstos. ${ }^{2,8}$ Durante un brote los casos están frecuentemente asociados epidemiológicamente, y aparecen dentro de un periodo de dos semanas después de la exposición inicial y la colonización. Los portadores pueden ser crónicos en $30 \%$ de los casos, intermitentes en $30 \%$, y transitorios en $40 \%$. Debido a que la colonización puede ser en algunos individuos un proceso inmunizante, la enfermedad se previene por la emergencia de anticuerpos protectores. Los estudios de portadores son muy controversiales y en ocasiones arrojan información contradictoria. ${ }^{7}$ La experiencia del análisis en diferentes grupos poblacionales, durante ocho años de epidemia, en Cuba, es útil para demostrarlo. En estos estudios no siempre coinciden las tasas más altas de portadores con la aparición de brotes. Debe tenerse en cuenta que las investigaciones de portadores no tienen valor para pronósticos individuales o colectivos, ya que el estado de portador es transitorio, repetitivo y variable. En epidemias la colonización puede ser sucesiva o simultánea por serogrupos iguales o diferentes. ${ }^{8}$

Cuando aparecen casos de enfermedad por N. meningitidis en una escuela, el riesgo de que otro estudiante pueda infectarse varía de 0.04 a $2.5 \%$, siendo mayor el riesgo en la secundaria que en la primaria. La variación en la tasa de ataque refleja la variación en la respuesta a la institución de medidas de control, pero también depende de la bacteria, de factores ambientales, y de los factores del huésped. ${ }^{1,2,7,8,19}$ Esto se ha observado en experimentos naturales, en los que la misma cepa bacteriana muestra diferentes tasas de ataque en diferentes escuelas. La cercanía de los asientos entre los estudiantes ha sido identificada como un factor de riesgo para la colonización. Escenarios similares hay en las cárceles, en donde el hacinamiento constituye un aspecto determinante para la tasa de colonización y en la aparición de casos. Se han identificado brotes por $N$. meningitidis serogrupo $C$ en cárceles, asociados a una sobrepoblación de $40 \%$ en estas instituciones. ${ }^{6,20}$ La identificación de casos en cárceles ha sido considerada como un indicador epidemiológico del inicio de un brote en la comunidad. ${ }^{6,20}$

A pesar de la histeria que provocan los brotes por Neisseria meningitidis, en realidad más de $95 \%$ de los casos en la mayoría de los países se presentan en forma esporádica. La única región en donde la morbilidad y la letalidad están asociadas a brotes diversos, y es comparable con las tasas endémicas de la enfermedad es en el cinturón de Lapeyssonie, en Africa subsahariana. ${ }^{10}$

Existen innumerables interrogantes acerca del comportamiento epidemiológico y de la trascendencia social de la enfermedad en diversas regiones del mundo; por ejemplo, históricamente, en Africa subsahariana había, cada 5 a 10 años, epidemias considerables, y actualmente su tendencia es a disminuir durante el periodo interepidémico, y a desarrollar epidemias todos los años, desconociéndose cuáles son las causas del inicio de los brotes, así como de su terminación. ${ }^{10}$ Esta región en Africa incluye a una serie de países que están sumidos en la falta de higiene y en la pobreza. La sequía y desertificación, como resultado de la deforestación indiscriminada, convierten el clima de esta zona en un terreno abonado para el desarrollo e incremento de ésta y otras enfermedades de transmisión 
respiratoria, porque tanto la ausencia de humedad como el polvo arenoso laceran la mucosa nasofaríngea y contribuyen a la entrada de los microrganismos. Además, el hacinamiento constituye un factor predisponente en la propagación de la enfermedad. La carencia absoluta de una infraestructura sanitaria para la población, que garantice los mínimos recursos para preservar la salud, hacen que las expectativas de vida sean mínimas y quizás todo esto explique en parte la situación, en esta región tan especial, de la enfermedad meningocóccica.

\section{La última gran epidemia de meningitis causada por Neisseria meningitidis registrada en México}

Durante el invierno de 1945, y hasta el 31 de agosto de 1949, en la ciudad de San Luis Potosí se registró la última gran epidemia nacional de meningococo en México. ${ }^{21,22}$ Durante este brote hubo aproximadamente 753 casos en todos los grupos de edad, que aparecieron en 339 niños, y constituyeron $45 \%$ del total. Estos casos fueron confirmados por cultivo de muestras de líquido cefalorraquídeo, utilizando el medio agar-nopal de Ramírez, pero este medio no demostró ser útil para hemocultivos. ${ }^{22}$ La mayoría de los casos se presentaron en niños desnutridos que habitaban los barrios más pobres de la ciudad de San Luis Potosí en las zonas en donde abundan las vecindades y la vida en promiscuidad, y el hacinamiento era la regla. En los registros publicados en 1949 se mencionan a la miseria, el frío y al trabajo intenso y precoz en la población afectada como factores predisponentes para la enfermedad. A todo ello se agregó la inhalación de polvo en gran proporción, debido a las excavaciones en la calles de la ciudad, llevadas a cabo para colocar la tubería del nuevo drenaje. Esto provocó posiblemente irritación local en la nasofaringe, facilitando la entrada del meningococo, similar a lo que se ha sugerido en el cinturón de meningitis en Africa durante la época de sequía y vientos en el desierto. ${ }^{21}$

Desde entonces, los informes sobre casos de meningococcemia o meningitis por meningococo han sido escasos en el ámbito nacional. Algunos de los casos esporádicos de los que se informó se relacionaron con el serogrupo A. México ha figurado como uno de los países que ha registrado menos casos de esta enfermedad en el mundo. Recientemente se han comunicado a la Secretaría de Salud un número creciente de casos asociados a $N$. meningitidis, serogrupo $C$, que aparecen, tanto en forma esporádica como en pequeños brotes, ya sea en el Distrito Federal o en algunos municipios del Estado de México (cuadro I). ${ }^{23}$
En las primeras semanas de 2004 también se observó un número creciente de casos que obligaron a una revisión de las medidas preventivas y de tratamiento de la enfermedad.

\section{Características microbiológicas y patogénesis}

Neisseria meningitidis es una bacteria Gram negativa aeróbica inmóvil, no esporulada, usualmente encapsulada y piliada, que se logra aislar en medio enriquecido GC suplementado, sin inhibidores cuando se aísla de líquido cefalorraquídeo, y con inhibidores cuando se buscan portadores; antes se aislaba en agar chocolate. ${ }^{1}$ Se clasifica en serogrupos de acuerdo con la reactividad inmunológica de su polisacárido capsular, que constituye la base para el desarrollo de vacunas de polisacáridos, actualmente disponibles. ${ }^{1,2} \mathrm{~A}$ pesar de que existen 13 serogrupos, la mayoría de la enfermedad meningocóccica en el mundo es causada por los serogrupos A y C, para los cuales la vacuna de polisacárido es efectiva, y por el serogrupo B, el cual contiene un polisacárido poco inmunogénico, debido

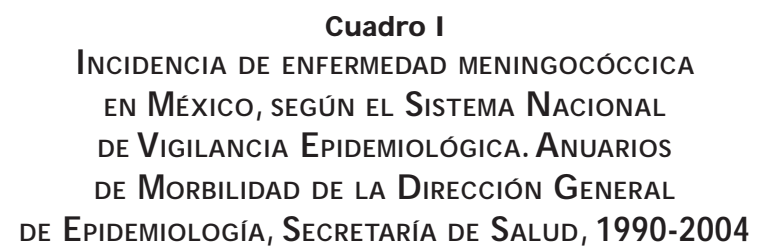

Año

Total de casos

\begin{tabular}{lc}
\hline 1990 & 8 \\
\hline 1991 & 3 \\
\hline 1992 & 19 \\
\hline 1993 & 10 \\
\hline 1994 & 51 \\
\hline 1995 & 73 \\
\hline 1996 & 0 \\
\hline 1997 & 39 \\
\hline 1998 & 37 \\
\hline 1999 & 4 \\
\hline 2000 & 2 \\
\hline 2001 & 24 \\
\hline 2002 & 78 \\
\hline 2003 & $5 *$
\end{tabular}

* Hasta la semana epidemiológica 04 (febrero 02, 2004)

salud pública de méxico / vol.46, no.5, septiembre-octubre de 2004 
posiblemente a su contenido de ácido polisiálico, que también se encuentra en células neuronales fetales en humanos. ${ }^{1}$ El polisacárido capsular está constituido por homopolímeros o heteropolímeros de unidades repetitivas de monosacáridos, disacáridos y polisacáridos. El componente que confiere la propiedad de invasividad a la bacteria es la presencia de derivados moleculares del ácido siálico en la cápsula del meningococo. Sin embargo, para el serogrupo A, el determinante principal es la molécula $\mathrm{N}$-acetil-manosamina-1-fosfato. La clasificación de $N$. meningitidis también puede hacerse por sus proteínas de membrana externa OMP en serosubtipos, de acuerdo con las proteínas de clase 1 de la membrana externa, o en serotipos, de acuerdo con las proteínas de clase 2 o 3 .

El meningococo tiene la capacidad para intercambiar material genético encargado de la producción de la cápsula y, por lo tanto, puede cambiar del serogrupo $\mathrm{B}$ al C, o viceversa. La identificación de clonas virulentas en los brotes se ha establecido a través de técnicas de electroforesis de campo pulsado (PFGE, por sus siglas en inglés) o técnicas de secuenciación molecular del ADN. Recientemente se ha identificado al lipooligosacárido (LOS), el cual determina inmunotipos diferentes de $N$. meningitidis, y constituye un importante factor determinante de invasividad. ${ }^{1,2,8}$

El proceso patogénico de $N$. meningitidis se inicia con la adherencia de la bacteria a la superficie de las microvellosidades del epitelio cilíndrico no-ciliado de la nasofaringe, en donde se multiplica. Los pili son las adhesinas que utilizan durante el contacto inicial con el receptor CD46, proteína presente como cofactor de la membrana. Las proteínas asociadas a la opacidad (Op), Opa y Opc, se unen al receptor CD66 y a los receptores proteoglicanos como heparán sulfato, respectivamente, lo cual inicia cambios en la conformación dados por rearreglos en la molécula de actina. La adherencia estimula la entrada de la bacteria a las células epiteliales, lo que le permite atravesar el epitelio mucoso mediante vacuolas fagocíticas. ${ }^{1,2}$ La producción de la cápsula se detiene a la entrada de la bacteria a las células epiteliales. La sobrevivencia del meningococo en las células epiteliales se favorece por: a) la producción de proteasa de IgA1, b) la proteína porB y c) al inactivar a la molécula LAMP1. La mayoría de las personas que se encuentran colonizadas con $N$. meningitidis permanecen asintomáticas; sin embargo, en un porcentaje menor, el meningococo penetra la mucosa y entra a la circulación, causando enfermedad sistémica. ${ }^{1,18}$ En algunas personas el proceso de colonización con N. meningitidis ocasiona la producción de anticuerpos protectores. ${ }^{8}$
Unicamente las cepas virulentas que encuentren a un huésped susceptible lo enferman; esto explica por qué existen relativamente pocos casos de enfermedad meningocóccica en relación con el vasto número de personas colonizadas. En una población determinada un incremento en la incidencia de casos de enfermedad meningocóccica refleja la introducción, transmisión y adquisición de una cepa virulenta de algún grupo clonal no existente en una población susceptible, y su diseminación se favorece por factores como el contacto cercano con otras personas, generalmente en áreas confinadas. Estas cepas bacterianas producen una cápsula que provee protección para evadir la respuesta inmune del huésped, particularmente la activación de los mecanismos de lisis, mediados por complemento, dependientes de anticuerpos. ${ }^{1,2}$ De la misma manera, contener pili, y los factores de adquisición de nutrientes -principalmente los mecanismos para obtener fierro de moléculas humanas, como la transferrina o lactoferrina- incrementan su potencial patogénico. La liberación de vesículas de la membrana externa que contienen lipooligosacárido, las proteínas de la membrana externa, fosfolípidos y polisacáridos capsulares se asocian también a la patogenicidad de las cepas con potencial invasivo. El meningococo, al igual que algunas bacterias, realiza un proceso de autolisis, libera ADN y componentes de la pared celular, que inducen la cascada inflamatoria.

La utilización de marcadores fenotípicos y de análisis de cepas aisladas mediante tipificación genómica, utilizando la técnica de electroforesis de enzimas multilocus (MLE, por sus siglas en inglés) para obtener electroferotipos (ET), y la tipificación por secuenciación de genes sirven para entender mejor la dinámica de la diseminación del meningococo y su asociación con los determinantes de virulencia o epitopos que inducen la inmunidad. ${ }^{1,8}$

Aquellos individuos que tienen alguna deficiencia en el sistema bactericida, dependiente de anticuerpos, mediado por complemento son susceptibles a contraer la enfermedad por meningococo. ${ }^{1}$ La correlación directa entre susceptibilidad a la enfermedad sistémica por meningococo y la ausencia de anticuerpos bactericidas detectables ha sido demostrada por estudios que identificaron que los reclutas militares que tienen anticuerpos bactericidas se asociaban frecuentemente con portadores asintomáticos, pero sin desarrollo de enfermedad. ${ }^{24-30}$

Diversos investigadores han demostrado claramente que la ausencia de anticuerpos bactericidas en presencia de colonización nasofaríngea con N. meningitidis se asocia al desarrollo de enfermedad. Por lo 
anterior, aquellos individuos que están predispuestos a la enfermedad meningocóccica incluyen personas en riesgo que han sido esplenectomizadas o con asplenia funcional, deficiencia de properdina y del componente terminal de la cascada del complemento. Sin embargo, a pesar de que estas personas tienen mayor riesgo de desarrollar la enfermedad por el meningococo constituyen únicamente una pequeña proporción del total de casos. ${ }^{1,2,7,8}$ Se piensa que los individuos infectados con el virus de la inmunodeficiencia humana probablemente también tengan un riesgo incrementado para la infección, pero no tan elevado como se ha visto en relación con otros organismos encapsulados. Otras características genéticas se han asociado a un incremento en el riesgo de la enfermedad como son polimorfismos en los genes para lectina, asociada a manosa, y los del factor de necrosis tumoral alfa. Algunos investigadores han demostrado la expresión de pilC, que es un pilus expresado in vivo, responsable de facilitar al meningococo el cruce de la barrera hematoencefálica. Asimismo han notado que las personas infectadas con Bacillus pumilus o E. coli con antígeno K1 pueden desarrollar respuesta protectora humoral cruzada contra meningococo, debido a que estas bacterias contienen moléculas inmunológica y químicamente similares a algunos antígenos capsulares del meningococo. ${ }^{1}$

La exposición activa o pasiva al humo del cigarro se ha considerado como un importante factor de riesgo para la enfermedad, así como la presencia de infección viral del tracto respiratorio superior. Se considera que la presencia de brotes asociados a las épocas de sequía en Africa podría condicionar un desecamiento y daño de la mucosa respiratoria nasofaríngea que permite la entrada de la bacteria. ${ }^{2}$ La disminución de la integridad física de la mucosa respiratoria es fundamental en la invasividad del meningococo. ${ }^{8}$

\section{Manifestaciones clínicas}

Uno de los grandes retos del diagnóstico de la enfermedad meningocóccica es que las manifestaciones clínicas son difíciles de distinguir de otras infecciones menos graves del tracto respiratorio superior. El cuadro de meningitis aguda purulenta es la forma usual de manifestación de la infección meningocóccica. ${ }^{1,2} \mathrm{Se}$ calcula que la infección de las meninges es el resultado de la diseminación hematógena de la bacteria, se observa en $50 \%$ de los pacientes y es similar en sus manifestaciones iniciales a otras meningitis bacterianas. Los síntomas se caracterizan por un inicio súbito de cefalea, fiebre, rigidez de nuca, náusea, vómito, fotofobia y alteraciones neurológicas que pueden in- cluir estupor, delirio, coma y convulsiones. En infantes, la meningitis puede tener un inicio más insidioso, con síntomas atípicos sin rigidez de nuca; sin embargo, el abultamiento de la fontanela puede ser característico. ${ }^{1,2,8}$ Además, hay irritabilidad y llanto inconsolable, vómito, convulsiones, rechazo al alimento e hipotonía.

Los hemocultivos son positivos en tres cuartas partes de los pacientes con meningitis meningocóccica. La meningococcemia es difícil de reconocer fuera del escenario de un brote; sin embargo, se caracteriza por el inicio súbito de fiebre, hay un exantema purpúrico o petequial que puede progresar a púrpura o septicemia fulminante, asociada a hipotensión, hemorragia adrenal aguda (Síndrome Waterhouse-Friderichsen) y, finalmente, a falla orgánica múltiple. ${ }^{1}$ En ocasiones el exantema asociado a enfermedad meningocóccica puede ser maculopapular, similar a un exantema viral, no prurítico, transitorio y usualmente con duración de aproximadamente dos días. El meningococo serogrupo $C$ causa una gran letalidad y se relaciona con una mayor incidencia de meningococcemia. Los serogrupos A y $\mathrm{C}$ se asocian principalmente a brotes de meningitis; sin embargo, también pueden presentarse como meningococcemia. ${ }^{2}$

Algunos investigadores han demostrado la presencia de niveles elevados del lipooligosacárido en plasma, en pacientes con meningococcemia, y bajos en líquido cefalorraquídeo; mientras que se ha identificado lo contrario en pacientes con meningitis. Esto se ha correlacionado también con los niveles del factor de necrosis tumoral e interleucina-1, como factores pronósticos de la enfermedad. En casos de sepsis grave, la activación de la vía de la proteína $C$ está alterada, lo cual se correlaciona con una disminución de la expresión de la trombomodulina a nivel endotelial. ${ }^{31}$

Neisseria meningitidis puede afectar al tracto respiratorio en la forma de neumonía, epiglotitis y otitis media. La neumonía se observa en 5 a 15\% de los casos con enfermedad meningocóccica invasiva, particularmente con los serogrupos Y, y W-135. ${ }^{11,13}$ El diagnóstico de la neumonía por meningococo se dificulta porque el aislamiento del meningococo de secreciones respiratorias no distingue a las personas que son portadoras asintomáticas de aquellas que tienen neumonía. Existen formas focales de infección que se dan en baja frecuencia como artritis séptica, uretritis, pericarditis y conjuntivitis. En el caso de la conjuntivitis, en 18\% de los casos puede pasar de un proceso local en conjuntiva para diseminarse y causar ya sea meningococcemia o meningitis bacteriana. ${ }^{13}$ La forma de meningococcemia crónica es muy rara y está caracterizada por fiebres intermitentes, exantema, artralgias y cefalea. ${ }^{1,2,7}$ 


\section{Diagnóstico}

El diagnóstico de la meningitis por meningococo se basa en la evaluación del líquido cefalorraquídeo; la punción lumbar constituye un aspecto fundamental (cuadro II). El diagnóstico microbiológico que se ha utilizado clásicamente para identificar a N. meningitidis y diferenciarla de otros patógenos comunes se basa en el cultivo en medio apropiado (Mueller-Hinton o GC enriquecido con suplemento, antes se empleaba agar chocolate). La sensibilidad disminuye significativamente si la terapia antimicrobiana ha sido iniciada antes de la toma del cultivo. La tinción de Gram del líquido cefalorraquídeo es un estudio importante para la identificación rápida y precisa de $N$. meningitidis (figura 1$) \cdot{ }^{1,2}$ Los equipos comerciales disponibles para detectar el antígeno de polisacárido en líquido cefalorraquídeo también son muy útiles para el diagnóstico presuntivo de la enfermedad, además de proporcionar información del serogrupo, pero pueden dar resultados falsos negativo, especialmente con el B. El serogrupo se identifica después del cultivo por aglutinación de la bacteria obtenida en cultivo puro a partir de las colonias, o directamente en el líquido cefalorraquídeo, ya que por aglutinación por látex se identifica el antígeno. Actualmente se han utilizado análisis por la reacción en cadena de la polimerasa (PCR, por sus siglas en inglés) en líquido cefalorraquídeo para identificar al serogrupo, y ofrece la ventaja de no requerir de organismos vivos para obtener un resultado positivo y tener una sensibilidad y especificidad mayor a $90 \%$. La mayor utilidad de esta técnica es que permite establecer el diagnóstico en individuos con cultivo negativo porque han recibido antibióticos previamente a la punción lumbar. ${ }^{2}$

Acompañando a las alteraciones del líquido cefalorraquídeo hay otros hallazgos que pueden aparecer en la biometría hemática, como leucocitosis, con incre- mento de polimorfonucleares. En casos de púrpura severa se puede encontrar trombocitopenia asociada a datos de coagulación intravascular sistémica (alteraciones de tiempo de coagulación y elevación de los productos de consumo de fibrinógeno). Los hemocultivos se reportan frecuentemente positivos y cuando hay lesiones purpúricas la observación directa al microscopio y el cultivo de especímenes tisulares o pus de lesiones pueden sustituir a los hemocultivos cuando éstos no pueden llevarse a cabo, siempre y cuando se tome oportuna y adecuadamente la muestra. ${ }^{1,2}$

El diagnóstico diferencial de la enfermedad meningocóccica se hace principalmente con las de otros patógenos que pueden ocasionar meningitis bacteriana como el Streptococcus pneumoniae y el Haemophilus influenzae. Es por lo anterior que la institución de terapia empírica para cubrir estos patógenos es fundamental, previo a la identificación del agente causal definitivo, ya sea en una tinción de Gram, cultivo, o

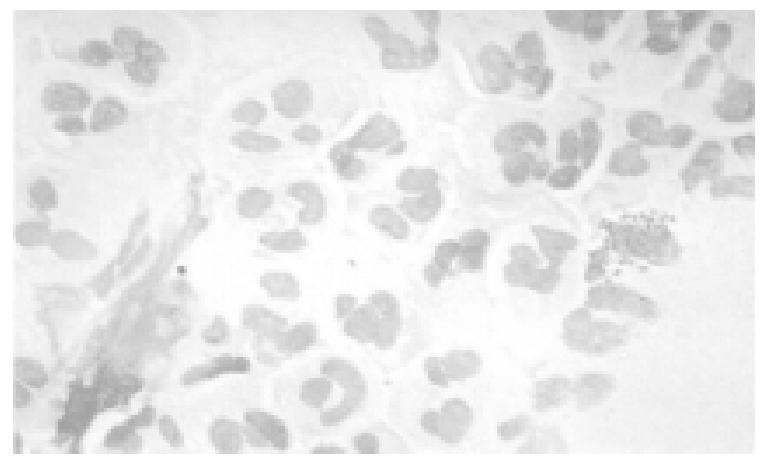

Figura 1.Tinción de Gram en líquido cefalorraquíDEO QUE MUESTRA LOS DIPLOCOCOS GRAM NEGATIVOS CARACTERÍSTICOS DE N EISSERIA MENINGITIDIS

\section{Cuadro II}

\section{Características del líQuido Cefalorraquídeo en la meningitis MENINGocóccica}

\begin{tabular}{|c|c|}
\hline Leucocitos & Usualmente más de 1000 células $/ \mathrm{mm}^{3}$ con más de $80 \%$ de polimorfonucleares* \\
\hline Proteínas & Elevadas, $>80 \mathrm{mg} / \mathrm{dl}^{\ddagger}$ \\
\hline Tinción de Gram & Diplococos Gram negativos intracelulares 0 extracelulares en $80 \%$ de los casos no tratados previamente \\
\hline Glucosa & $<40 \mathrm{mg} / \mathrm{dl}$ \\
\hline
\end{tabular}

Fuente: referencia 2 
mediante pruebas de aglutinación en el líquido cefalorraquídeo. ${ }^{32}$ La meningococcemia es difícil de distinguir de otras entidades febriles agudas, particularmente cuando no está presente el exantema purpúrico; sin embargo, la asociación entre fiebre, púrpura y choque es altamente sugestiva de enfermedad meningocóccica.

\section{Tratamiento}

A principios del siglo XX la mortalidad por enfermedad meningocóccica era de 70\%, la utilización de terapia con sueros y, posteriormente, de sulfonamidas provocó, hace muchos años, un descenso en la letalidad de la enfermedad. No obstante, a pesar de la utilización de antibióticos y manejo de soporte adecuado, la tasa de letalidad ha permanecido estable en los últimos 20 años, en aproximadamente 9 a $12 \%$, ya que los pacientes con meningococcemia presentan una mortalidad de hasta $50 \% .{ }^{1,2}$ El manejo clínico de un paciente con enfermedad meningocóccica, ya sea meningococcemia o meningitis, siempre debe tomarse como una urgencia médica. El paciente debe ser admitido al hospital o centro de salud para el diagnóstico y tratamiento. En general, debido a que la contagiosidad del paciente es moderada y desaparece rápidamente después de comenzar la terapia antimicrobiana, el aislamiento del paciente no se considera fundamental. Debido a los riesgos de secuelas y de muerte, la institución de terapia antimicrobiana debe realizarse lo antes posible frente a la sospecha de un caso. Son fundamentales la toma de hemocultivos y la punción lumbar para hacer el estudio microbiológico, de ser posible, siempre previo a la administración de antibióticos, los cuales deben administrarse inmediatamente después, ante la sospecha clínica de meningitis bacteriana, sin la necesidad de esperar a los resultados de los estudios de laboratorio.

Los antimicrobianos que han resultado efectivos contra N. meningitidis incluyen a la penicilina G, derivados beta lactámicos, combinaciones ampicilina sulbactam, amoxicilina, ácido clavulánico y cefalosporinas como cefuroxime y cefepime. La penetración al líquido cefalorraquídeo y la susceptibilidad de la bacteria al antibiótico son fundamentales. Existen, afortunadamente, niveles bajos de resistencia a la penicilina, lo cual permite continuar utilizándola, o a la ampicilina, como antibióticos de primera línea para tratar la enfermedad por meningococo. El cloranfenicol es una buena alternativa. Las cefalosporinas de tercera generación, como la ceftriaxona o la cefotaxima, son excelentes alternativas, pero su costo es más elevado. Sin embargo, en muchas ocasiones la ceftriaxona se convierte en la alternativa ideal, debido a que puede ser administrada una vez al día con periodos tan cortos como dos días, mientras que el tratamiento con penicilina o ampicilina requiere de por lo menos cinco días. El trimetoprim-sulfametoxazol no se recomienda a menos que el antibiograma de las cepas aisladas demuestre susceptibilidad. En general, en los aislamientos de $N$. meningitidis no se recomienda hacer antibiograma, a menos que la situación clínica lo amerite. ${ }^{1,2}$ La ruta de administración de elección es la intravenosa; no obstante, hay diversos estudios clínicos que han demostrado que la utilización de cloranfenicol intramuscular (forma aceitosa) o de ceftriaxona son alternativas aceptables si las condiciones no permiten la utilización de la vía intravenosa (cuadro III).

Las elevadas tasas de morbilidad y mortalidad asociadas a la enfermedad meningocóccica, aun en pacientes que han recibido terapia antimicrobiana adecuada, han sugerido que posiblemente algunas terapias antinflamatorias podrían coadyuvar a mejorar el pronóstico clínico. Se ha calculado que entre 11 a 19\% de los sobrevivientes a la enfermedad por meningococo quedan con secuelas como sordera y otras alteraciones neurológicas, o con pérdida de un miembro en casos de meningococcemia. La utilización rutinaria de corticosteroides como dexametasona, para disminuir la inflamación meníngea provocada por la muerte bacteriana previo a la iniciación de antimicrobianos, ha sido sugerida en diversos estudios, pero no existe una recomendación oficial para su uso. Tradicionalmente, se ha considerado que pacientes con daño neurológico ocasionado por la inflamación meníngea identificada al momento del diagnóstico, y la presencia de una tinción de Gram sugerente para N. meningitidis se consideran dos situaciones clínicas en las cuales la utilización de esteroides puede disminuir las secuelas y, probablemente, mejorar la sobrevida de estos pacientes. ${ }^{32-34}$

La duración recomendada del tratamiento, en general, es de siete días en la mayoría de los países. Sin embargo, existe suficiente evidencia que indica que si la meningitis meningocóccica se trata durante cuatro días con penicilina $G$, a las mismas dosis, es tan efectiva como si se tratara por más tiempo.

Aunado a la terapia antimicrobiana es fundamental el manejo adecuado de líquidos y de electrolitos. Si el paciente se encuentra inconsciente o vomita, y si no se puede instalar una vía intravenosa, en ocasiones la inserción de sonda nasogástrica puede ser de gran utilidad. Cuando se requiera, la utilización de anticonvulsivantes o antieméticos puede ser muy útil. El incremento de la presión intracraneal asociada con la inflamación meníngea contribuye significativamente a la morbilidad y mortalidad. Por lo anterior, la ventilación mecánica con hiperventilación puede mejorar este estado. Se recomienda el manejo de pacientes con 


\section{Cuadro III \\ Antibióticos utilizados Para tratar enfermedad POR N EISSERIA M EN IN Gitidis}

\begin{tabular}{|c|c|c|c|c|}
\hline Antibiótico & Dosis adultos & Dosis niños & Vía de administración & Duración del tratamiento \\
\hline Penicilina G & 3-4 MU cada 4-6 horas & $400000 \mathrm{U} / \mathrm{kg}$ & Intravenosa & $\geq 4$ días \\
\hline Ampicilina 0 amoxicilina & $2-3$ g cada 6 horas & $250 \mathrm{mg} / \mathrm{kg}$ & Intravenosa & $\geq 4$ días \\
\hline Cloranfenicol & 1 g cada 8 horas & $100 \mathrm{mg} / \mathrm{kg}$ & Intravenosa* & $\geq 4$ días \\
\hline Cefotaxime & 2 g cada 6 horas & $250 \mathrm{mg} / \mathrm{kg}$ & Intravenosa & $\geq 4$ días \\
\hline Ceftriaxona & 2 g cada 12 horas & $50-80 \mathrm{mg} / \mathrm{kg}$ & Intravenosa & $\geq 4$ días \\
\hline Ceftriaxona & $2 \mathrm{~g}$ dosis única & $50-80 \mathrm{mg} / \mathrm{kg}$ & Intramuscular & 1-2 días \\
\hline
\end{tabular}

MU = millones de unidades

Fuente: referencia 2

enfermedad severa, aquellos con choque séptico, púrpura fulminante, o en estado de coma por meningitis, con una terapia intensiva y personal entrenado para tratar estos casos. ${ }^{2}$

\section{Medidas de control y prevención}

La enfermedad meningocóccica es potencialmente prevenible a través de vacunación y quimioprofilaxis en circunstancias específicas. En 1937, la terapia con sulfonamidas cambió significativamente el pronóstico de la infección por meningococo. ${ }^{2}$ La profilaxis tenía el objetivo de erradicar el estado de portador y se constituyó en un método simple y seguro para la prevención de brotes, particularmente en el hacinamiento característico de los cuarteles militares. No obstante, con la aparición de cepas resistentes a las sulfonamidas, la necesidad de estrategias de inmunoprevención proporcionó el escenario para el desarrollo de vacunas seguras y efectivas, las cuales son utilizadas actualmente. En algunos países con tasas endémicas elevadas el esquema universal de vacunación incluye la inmunización contra el meningococo. Sin embargo, es de gran utilidad emplear las vacunas disponibles, sobre todo para el control de brotes en diversas regiones del mundo. ${ }^{23-31,35-37}$ Se ha estimado que el control de la transmisión a través de la inmunoprofilaxis con vacunas que protejan contra cepas virulentas de grupos clonales de $N$. meningitidis eliminaría aproximadamente $75 \%$ de la enfermedad endémica y la mayoría de los brotes epidémicos. ${ }^{8}$

\section{Quimioprofilaxis}

El objetivo de la quimioprofilaxis es prevenir la aparición de casos secundarios al eliminar el estado de por- tador con Neisseria meningitidis. La quimioprofilaxis es una medida importante de control de la enfermedad; sin embargo, tiene muchas limitaciones y su uso se debe restringir a circunstancias especiales. Estas situaciones incluyen contactos cercanos a un caso, lo que en general se refiere a los contactos intradomiciliarios institucionales, ya sea en escuelas, cuarteles militares, cárceles, en guarderías, y en aquellos individuos que han tenido contacto con secreciones orales del paciente, ya sea por besos o por compartir comida o bebidas. Se recomienda que aquellos pacientes tratados en un hospital o clínica, con el diagnóstico de enfermedad por meningococo, y que han recibido tratamiento con un agente que no elimina el estado de portador (penicilinas o cloranfenicol) reciban quimioprofilaxis con un agente efectivo (ciprofloxacina, rifampicina o ceftriaxona) al momento de darse de alta. La utilización de quimioprofilaxis masiva poblacional no la recomienda ninguna autoridad de salud durante un brote epidémico. ${ }^{1,2}$

Debido a que el riesgo de casos secundarios en los contactos cercanos del caso índice es muy elevado en los primeros días, esta terapia se debe iniciar lo antes posible, preferiblemente dentro de las primeras 48 horas del contacto. Si se administra después de 14 días del inicio del cuadro clínico del caso índice, probablemente esta terapia no tenga ningún impacto clínico. Los casos secundarios usualmente se presentan dentro de los 10 días posteriores a la exposición; por lo cual se recomienda vigilancia estrecha de este grupo por lo menos durante 10 días para asegurar la instauración de tratamiento adecuado y a tiempo en casos secundarios, que pueden aparecer muchas veces a pesar del establecimiento de quimioprofilaxis. ${ }^{1,8}$

La quimioprofilaxis es efectiva únicamente cuando se administra con antibióticos sistémicos, ya que la utilización de los tópicos no ha demostrado ser 
efectiva (cuadro IV). Dentro de los agentes potencialmente valiosos, el más frecuentemente utilizado es la rifampicina. ${ }^{1,2}$ Sin embargo, la utilización de ciprofloxacina oral en una sola dosis ofrece una alternativa importante, pues además del apego -al ser una dosis única y tener la misma efectividad que la rifampicina- desde el punto de vista logístico el tratamiento se facilita. Además, la rifampicina constituye el principal fármaco en el control de la tuberculosis, y la utilización excesiva poblacional, y en situaciones de histeria, podría condicionar la aparición de tasas elevadas e inaceptables de resistencia a la rifampicina. El inconveniente más importante de la utilización de la ciprofloxacina sobre la rifampicina es quizá un mayor costo de la primera. La utilización de ciprofloxacina durante la infancia, especialmente cuando se aplica como dosis única, no se ha asociado a toxicidad, por lo cual representa una alternativa de quimioprofilaxis durante esta etapa. ${ }^{37}$ Asimismo, la ceftriaxona administrada en forma intramuscular ofrece una tercera alternativa de gran efectividad, pero de costo elevado. ${ }^{2}$ El empleo de penicilinas y cloranfenicol por vía oral o intramuscular, no se recomienda por su demostrada inefectividad. ${ }^{1,2}$

\section{Vacunación}

Se ha demostrado que en algunos individuos el estado de portador constituye un proceso inmunizante. Los polisacáridos específicos de cada serogrupo, con excepción del B, han sido reconocidos como los blancos para la actividad bactericida que se desarrolla en personas colonizadas con $N$. meningitidis, y esa información ha constituido la base para el desarrollo de vacunas contra el meningococo. ${ }^{23-30}$ Existen vacunas de polisacáridos capsulares contra los serogrupos A, C, Y y W135 que han demostrado eficacia de 75 a $90 \%$ en adultos $y$ en niños en edad escolar, pero en menor medida en los menores de dos años. Las vacunas de polisacáridos capsulares disponibles proporcionan protección sistémica en sólo algunos segmentos de la población y, en general, tienen un efecto marginal en el estado de portador o en la adquisición de nuevas cepas. Por lo tanto, no resulta sorpresivo que estas vacunas hayan tenido un efecto limitado en el control de la enfermedad meningocóccica. En el desarrollo de vacunas antimeningocóccicas, la estimulación de la inmunidad de grupo al reducir el porcentaje de portadores, y la adquisición de cepas virulentas del meningococo entre adolescentes y adultos, se ha considerado una estrategia fundamental en el control de esta devastadora infección. ${ }^{1,2}$

Goldschneider, Gotschlich y Artenstein iniciaron en 1966 estudios sobre la inmunidad humana frente al meningococo y relacionaron la susceptibilidad a la enfermedad meningocóccica con la ausencia de anticuerpos bactericidas en el suero. ${ }^{23-25,27}$ La vacuna antimeningocóccica monovalente $C$ fue obtenida por Gotschlich y colaboradores en 1969, y se hallaba integrada por polisacáridos capsulares específicos del serogrupo C, con un peso molecular superior a 100000 daltons (D) y menos de 1\% de proteínas, ácidos nucleicos y lipooligosacáridos con actividad endotóxica. Estos investigadores detectaron anticuerpos bactericidas en el suero de seis voluntarios a quienes se les había administrado la vacuna una semana antes y éstos alcanzaron su título máximo a las dos semanas. Esta vacuna antimeningocóccica fue la primera que se administró a gran escala, ensayada inicialmente en los centros estadounidenses de instrucción militar básica. ${ }^{27}$

Se ha sugerido en varios estudios que los niveles protectores de anticuerpos no parecen persistir en la mayoría de los niños inmunizados con vacuna $\mathrm{C}$ más allá de los dos años de edad, mientras que en adultos el descenso de la concentración de anticuerpos anti-C

\section{Cuadro IV \\ ESQUEMAS DE QUIMIOPROFILAXIS PARA NEISSERIA MENINGITIDIS}

\begin{tabular}{|c|c|c|}
\hline M edicamento & Grupo de edad & Dosis \\
\hline Ciprofloxacina & $\begin{array}{l}\text { Niños } \\
\text { Adultos }\end{array}$ & $\begin{array}{l}20 \mathrm{mg} / \mathrm{kg} \text {, dosis única } \\
\text { Suspensión de } 250, \mathrm{mg} / 5 \mathrm{ml} \\
\text { Tableta de } 500 \mathrm{mg} \text {, dosis única }\end{array}$ \\
\hline Rifampicina & $\begin{array}{l}\mathrm{N} \text { iños menores de } 1 \text { mes } \\
\mathrm{N} \text { iños mayores de } 1 \text { mes } \\
\text { Adultos }\end{array}$ & $\begin{array}{l}5 \mathrm{mg} / \mathrm{kg} \text {, dos veces al día, por dos días } \\
10 \mathrm{mg} / \mathrm{kg} \text {, dos veces al día, por dos días } \\
600 \mathrm{mg} \text {, dosis única (dos cápsulas de } 300 \mathrm{mg} \text { ) }\end{array}$ \\
\hline Ceftriaxona & $\begin{array}{l}\text { Menores de } 15 \text { años } \\
\text { Mayores de } 15 \text { años y adultos }\end{array}$ & $\begin{array}{l}125 \text { mg, dosis única, intramuscular } \\
250 \text { mg, dosis única, intramuscular }\end{array}$ \\
\hline
\end{tabular}

Fuente: referencias 1,2 
no es tan rápido. La reinmunización con vacuna $C$ antes de los 18 meses de edad en niños que habían sido primovacunados a los tres meses de edad mostró una mayor eficacia. ${ }^{27}$

Los principales responsables de la enfermedad meningocóccica en el mundo son los serogrupos B, A, $\mathrm{C}, \mathrm{Y}$ y W-135. Dado que la vacuna protege frente a cuatro de estos cinco serogrupos, el problema residiría en el serogrupo B, que además resulta ser el más frecuentemente aislado en el mundo. Se han realizado varios ensayos de vacuna contra este serogrupo; While, en 1972, obtuvo una vacuna de polisacárido capsular específico, pero la respuesta fue débil. ${ }^{34}$

El polisacárido B también tiene escasa inmunogenicidad en las infecciones naturales, ya que es frecuente que no se consiga demostrar la presencia de anticuerpos anti-B durante o después de la enfermedad meningocóccica, o ser portador nasofaríngeo de meningococo $\mathrm{B} .{ }^{1}$

Debido a esta escasa inmunogenicidad se han ensayado varias estrategias empleando como vacunas potenciales otros componentes de la superficie bacteriana. Entre ellas se incluyen modificaciones del polisacárido B, mediante enlace covalente con toxoide tetánico, vacunas de proteínas ligadoras de hierro, vacunas de pili y proteasa de IgA. Las proteínas principales de la membrana externa del meningococo $B$ son capaces de inducir formación de anticuerpos bactericidas, y ello las hace candidatas a ser constituyentes de la vacuna; ya se han ensayado diferentes candidatos para éstas, pero su prueba de eficacia no ha resultado satisfactoria.

La única vacuna aprobada para su uso es la antimeningocóccica cubana BC, cuya eficacia de $83 \%$ fue comprobada en su estudio de fase II placebo-vacuna, realizado en Cuba cuando ya habían transcurrido ocho años de epidemia. ${ }^{36,37}$

La utilización de vacunas conjugadas que inducen memoria inmunológica celular ofrece, probablemente, la mejor opción de inmunoprofilaxis, por suministrar niveles adecuados de protección asociados a la disminución en el porcentaje de portadores en la comunidad, como se ha demostrado para la vacuna conjugada de Hemophilus influenzae. De éstas, la única disponible es la del serogrupo $C$, ampliamente utilizada en el Reino Unido. ${ }^{23}$

\section{Conclusiones}

La enfermedad ocasionada por $N$. meningitidis continúa siendo una de las principales causas de meningitis bacteriana y sepsis en el mundo. Las medidas principales para su control son la inmunoprofilaxis y el diagnóstico certero y oportuno, de preferencia con cultivo microbiológico. Las vacunas conjugadas ofrecen tener un mayor impacto poblacional por su efecto al disminuir el porcentaje de portadores asintomáticos. La institución de antibioticoterapia en todos los casos, así como la utilización de quimioprofilaxis en contactos cercanos constituyen medidas de control adicionales. Debido a que la quimioprofilaxis es en muchos casos insuficiente, la vigilancia estrecha de los contactos es fundamental para identificar y tratar tempranamente a los casos secundarios.

\section{Referencias}

1. Rosenstein NE, Perkins BA, Stephens DS, Popovic T, Hughes JM. Meningococcal disease. N Engl J Med 2003, 344(18):1378-1388. 2.W orld Health 0 rganization. Control of epidemic meningococcal disease.W HO Practical guidelines. $2^{\mathrm{a}}$ Ed. Disponible en: http:// www.who.int/emc.

3. Peltola H. Meningococcal disease: Still with us. Rev Infect D is 1983.5(1):71-91.

4.Tikhomirov E, Santamaría M, Estevez K. Meningococcal disease: Public health burden and control.W orld Health Stat Q 1997;50(3/4):170-177. 5. Musher D. How contagious are common respiratory tract infections? N Engl J Med 2003; 348(13):1256-1266.

6. N elson JD. Jails, microbes, and the three-foot barrier. N Engl J Med 1996; 335(12):885-886.

7. Schwartz B, Moore PS, Broome CV. Global epidemiology of meningococcal disease. Clin Microbiol Rev 1989;2 suppl:S118-S124. 8. Stephens DS. Uncloaking the meningo coccus: D ynamics of carriage and disease. Lancet 1999;353:941-942.

9. 0 ffit PA, Peter G.The meningococcal vaccine- public policy and individual choices. N Engl J Med 2003;349(24):2353-2356.

10. Pollard AJ, Santamaría M, Maiden MC.W -135 Meningococcal disease in Africa. Emerg Infect D is 2003;9(11). Disponible en http:// www.cdc.gov/ncidod/EID/vol9no11/02-0727.htm.

11. Centers for Disease Control and Prevention. Serogroup Y meningo coccal disease - Illinois, C onnecticut, and selected areas, U nited States, 1989-1996. MMW R Morb Mortal W kly Rep 1996;43(46):10101014.

12. Ministerio de Salud Pública de Cuba. Enfermedad meningocócica. Cuadro Epidemiológico N acional, C uba, 1989. Ciudad de La Habana: MIN SAP; 1990.

13. Programa $\mathrm{N}$ acional de Inmunizaciones de Cuba. A plicación de VAMEN GOC - BC ®. Dirección N acional de Epidemiología. Ciudad de La Habana, Cuba: MIN SAP;1991.

14. Galiano LA, Echeverry ML. Efectividad de una vacuna antimeningocócica en una cohorte de Itaguí, Colombia, 1995. Boletín Epidemiológico de Antioquia 1995;2: 20.

15. Centers for D isease Control and Prevention. 0 utbreaks of group B meningococcal disease - Florida, 1995 and 1997. MMW R Morb Mortal W kly Rep 1998; 47(39):833-837.

16. Centers for D isease Control and Prevention. Control and prevention of meningococcal disease. Recommendations from the Advisory Committee on Immunization Practices (ACIP). MMW R Morb Mortal W kly Rep 1997; 46(RR-5):1-51.

17. Pirez MC, Picón T, G alazka J, Q uian J, Gutiérrez S, Ferrari AM et al. Enfermedad invasiva meningocóccica en Uruguay. Informe 
epidemiológico y recomendaciones, mayo 2002. Rev Med U ruguay 2002; 18:83-88.

18. N eal KR, N guyen-Van-Tam JS, Jeffrey N, Slack RCB, Madeley RJ, AitTahar $\mathrm{K}$ et al. Changing carriage rate of Neisseria meningitidis among university students during the first week of term: Cross sectional study. BMJ 2000; 320:846-849.

19. Reingold AL, Broome CV, Hightower A, Ajello GW, Bolan GA, Adamsbaum $C$ et al. Age specific differences in duration of clinical protection after vaccination with meningococcal polysaccharide $\mathrm{A}$ vaccine. Lancet 1985; 2 (8447):114-118.

20. Tappero JW, Reporter R, W enger JD,W ard BA, Reeves MW, Missbach TS et al. Meningococcal disease in Los Angeles C ounty, C alifornia, and among men in the county jails. N Engl J Med 1996; 335(12):833-840.

21. Padron F. Meningitis meninogocóccica en los niños. Rev Med Hosp Central San Luis Potosi 1949;1:193-218.

22. Gama y Silva JJ. Meningitis cerebro-espinal en San Luis Potosí, SLP. Estudio previo químico-clínico y bacteriológico. San Luis Potosi: Ediciones de la Universidad Autónoma de San Luis Potosí; 1946:7-36.

23. Sistema $\mathrm{N}$ acional de Vigilancia Epidemiológica. A nuarios de Morbilidad de la Dirección General de Epidemiología 1992-2004. Disponible en: http://www.dgepi.org.mx.

24. Cheesbrough JS, Morse AP, Green DR. Meningococcal meningitis and carriage in western Zaire:A hypo endemic zone related to climate. Epidemiol Infect 1995: 114: 75-92.

25. Mohammed I, Zaruba K. Control of epidemic meningococcal meningitis by mass vaccination. Lancet 1981;(11): 80-83.

26. Goldschneider Y, Lipow ML, G otschlich EC, Mauck FT, Bach IF, Randolph M. Immunogenicity of group A and group C meningococcal polysaccharides in human infants. J Infect $D$ is 1973;128(6):769-776. 27. Gold R, Lipow ML, Goldschneider Y, D raper TL, Gotschlich EC. $C$ linical evaluation of group $A$ and group $C$ meningococcal

polysaccharide vaccines in infants. J C lin Invest 1975;56:1536-1547.
28. D evine LF, Pierce W E, Floyd TM. Evaluation of group C meningo coccal polysaccharide vaccines in marine recruits. Am J Epidemiol 1970;92:25-32.

29. Jennings HJ, Lugowski C. Immunochemistry of groups $A, B$, and $C$ meningo coccal polysaccharide tetanus toxoid conjugates. I Immunol 1981;127:1011-1018.

30. Mohammed I \& Zaruba K. Control of epidemic meningococcal meningitis by mass vaccination. Lancet 1996;11:80-82.

31. Faust SN, Levin M, Harrison O B, Goldin RB, Lockhart MS, Kondaveeti $S$ et al. Dysfunction of endothelial protein $C$ activation in severe meningococcal sepsis. N Engl J Med 2001;345:408-416. 32. Tunkel AR, Scheld W M. Corticosteroids for everyone with meningitis? N Engl J Med 2002; 347:1613-1615.

33. Q uagliarello VJ, Scheld W M. D rug therapy:Treatment of bacterial meningitis. N Engl J Med 1997;336:708-716.

34. Tabas JA, Chambas HF,Tancredi D, Binder W B, A brilV, O rtega E et al. D examethasone in adults with bacterial meningitis. $N$ Engl J Med 2003;348:954-957

35. De Moraes JC, Perkins BA, Camargo MD, Rosseto NT, Barbosa HA, Tabares $C$ et al. Protective efficacy of serogroup $B$ meningococcal vaccine in São Paulo, Brazil. Lancet 1992;1074-1078.

36. Zollinger W D, Mandrell RE, Griffis JM, Altieri P, Berman S. Complex of meningococcal vaccine serogroup $B$ polysaccharide and type 2 outer membrane protein immunogenic in man. J C lin Invest 1989;63:836-848. 37. Gendrel D, Chalumeau M, Moulin F, Raymond J. Fluoroquinolones in paediatrics:A risk for the patient or for the community? Lancet Infect $D$ is 2003;3:537-546 